\title{
Antidepressant and anxiolytic effects of Garcinia indica fruit rind via monoaminergic pathway
}

\author{
Isha Dhamija ${ }^{1} \cdot$ Milind Parle $^{1} \cdot$ Sandeep Kumar $^{2}$
}

Received: 29 September 2016/ Accepted: 6 February 2017/Published online: 8 June 2017

(C) Springer-Verlag Berlin Heidelberg 2017

\begin{abstract}
Depression and anxiety are the most crippling neuropsychiatric disorders of this modern era. These mostly occur as anxiety followed by depression or in mixed state. Therefore, there is an urgent need of a safe and effective treatment, which proves its worth in this ailment. What else than a conventional food would be a better choice for a convenient therapy. Therefore, Garcinia indica, commonly known as Kokam, fruit rind has been used in the present study to investigate its antidepressant and anti-anxiety potential using forced swim test, tail suspension test, and reserpine-induced hypothermia; and elevated plus maze, hole-board test, and light dark model, respectively. Garcinia indica fruit rind given to mice with food for consecutive 14 days at $0.5,1$, and $2 \% \mathrm{w} / \mathrm{w}$ significantly $(p<0.05)$ reduced despair behavior in forced swim test, immobility duration in tail suspension test, and also switched the hypothermia (reserpine induced) to normal temperature significantly $(p<0.05)$. Garcinia indica significantly $(p<0.05)$ raised the time elapsed and count of entries in open arms of elevated plus maze, enhanced incidence of head dipping in holes of hole board along with duration of expending time in lit compartment of light dark model, exhibiting its anti-anxiety effect. Garcinia indica significantly reduced monoamine oxidase and
\end{abstract}

Isha Dhamija

ishaa25@gmail.com

Sandeep Kumar

katariatniper@gmail.com

1 Department of Pharmaceutical Sciences, Guru Jambheshwar University of Sciences and Technology, Hisar, Haryana, India

2 Department of Biotechnology, National Institute of Technology, Jalandhar, Punjab 144011, India malondialdehyde levels providing support to neuroprotective potential of fruit rind. The mechanistic study showed the participation of $G$. indica at $\alpha_{1}$-adrenoceptor and $\mathrm{D}_{2}$ dopamine receptor, by attenuating prazosin and sulpirideinduced increase in immobility duration. Garcinia indica fruit rind showed a significant antidepressant and anxiolytic effect while no effect on locomotor activity, i.e., no psycho-stimulation.

Keywords Garcinia indica · Rind · Anxiety · Depression · Malondialdehyde $\cdot$ Monoamine oxidase-A and B

\section{Introduction}

Chronic use of available pharmacological agents (especially chemically synthesized) is associated with serious adverse events. Therefore, there is a need of alternative, safe, and effective way to combat with various ailments. New era is moving towards use of herbal compound, nutrients, and supplements as a choice of therapy instead of allopathic medicines (Braithwaite et al. 2014). It is nothing better if we keep ourselves away from diseases, or if diseased, being treated by ingesting specific edible thing, such as fruits or vegetables or some condiment, as such if taken in an optimum amount. Fruits and vegetables, i.e., functional foods, are found to be a good source of natural antioxidants for dietary prevention of degenerative diseases, e.g., dietary soy for attenuation of hypertension in female spontaneously hypertensive rats (Martin et al. 2001; Shui and Leong 2006), dietary tamarind, sesame for anxiolytic and antidepressant activity (Dhamija and Parle 2012; Kumar et al. 2011; Parle and Dhamija 2012, 2013b), Punica granatum (pomegranate) (Hadipour-Jahromy and Mozaffari-Kermani 2010), Curcuma domestica (turmeric) 
(Kuptniratsaikul et al. 2009) and Zingiber officinale (ginger) (Altman and Marcussen 2001) for osteoarthritis, and so on.

One of such dietary supplement is Garcinia indica choisy, commonly known as Kokam which is generally found in Western Ghats of India. Kokam is used as condiment in making many Indian cuisines (Yamaguchi et al. 2000). All parts of Kokam, i.e., fruit, rind, seed, etc., have plenty of health benefits. Its various kinds of drinks are very beneficial and most liked by the people of South India. It provides cooling effect and prevents from heat stroke (Malik et al. 2005). The conventional uses of Kokam encompass mainly as sharbat (a sweet drink), acidulant in many Indian dishes, tumor, edema, gastric problems, burns, and irregular menstruation (Kunnumakkara et al. 2009; Mayura et al. 2014; Nayak and Rastogi 2010; Swami et al. 2014). Due to its anorectic properties, Kokam juice is utilized as weight loss supplement as well (Swami et al. 2014). Pharmacological studies reveal its possibility to use clinically as cardiotonic (Hemshekhar et al. 2011), hepatotonic (Deore et al. 2011), anti-inflammatory activity (Khatib et al. 2010), anti-bacterial, anti-fungal (Chatterjee et al. 2005; Varalakshmi et al. 2010), anti-cancer (Ding et al. 2006; Elisia and Kitts 2008), anti-obesity (Darji et al. 2010; Preuss et al. 2004), antioxidant (Ding et al. 2006; Selvi et al. 2003), neuroprotective effect (Antala et al. 2012), and hypoglycemic activity (Yamaguchi et al. 2000). Phytoconstituents present in $G$. indica include bezophenones, flavonoids, phenolic acids, lactones, and xanthones (Selvi et al. 2003). Leaves consist of citric acid, hydroxycitric acid lactones, and large amount of L-leucine (Jayaprakasha and Sakariah 2002). Kokam fruit is also rich in organic acid content such as malic acid, citric acid, acetic acid, ascorbic acid, hydroxycitric acid, and garcinol. In addition, Kokam rind contains pigment as a mixture of two anthocyanins, namely, cyanidin-3-sambubioside and cyanidin-3-glucoside (Krishnamurthy et al. 1982). The main component of rind of Kokam is garcinol, isogarcinol, and camboginol, while the ripened rind contains hydroxyacetic acid and hydroxycitric acid (HCA) along with (Jagtap et al. 2015; Parle and Dhamija 2013a).

A vast range of health benefits of various parts of Kokam justifies its exploration as a suitable functional food for neuroprotection in mental health disorders. Moreover, its isolated constituents such as garcinol, hydroxycitric acid, and Cyanidin-3-glucoside, were also effective in neuroprotection (Antala et al. 2012; Chen et al. 2009; Liao et al. 2005; Ohia et al. 2000).

In the present research work, anxiolytic and antidepressant activity of Kokam as functional food was investigated in rodents by studying behavioral and biochemical parameters. To the best of our knowledge and thorough literature review, Kokam as functional food has not yet been explored for psychological disarray.

\section{Materials and methods}

\section{Drugs and chemicals}

Fluoxetine hydrochloride, imipramine hydrochloride, $p$ chloro-phenylalanine ( $p$-CPA), prazosin, sulpiride (SigmaAldrich, St. Louis, USA); serotonin, reserpine, benzylamine, thiobarbituric acid (Hi Media laboratories, Mumbai), and diazepam injection (Calmpose ${ }^{\circledR}$, Ranbaxy, India) were used in this experimental work.

\section{Plant material}

Garcinia indica Linn. (family Clusiaceae, commonly known as Kokam) was selected for this study. Kokam rind was procured from Bangalore. The procured Kokam fruit rind got authenticated from Raw Materials Herbarium and Museum, National Institute of Science Communication and Information Resources, New Delhi (Reference NumberNISCAIR/RHMD/2013/2201/207). Kokam rind was triturated in mortar and pestle and was mixed with diet.

\section{Experimental animals}

Swiss albino mice (20-25 g) and Wistar rats (180-200 g) were used for this study and were procured from Disease Free Small Animal House in the premises of Lala Lajpat Rai University of Veterinary and Animal Sciences, Hisar (Haryana), India. Animals were kept in our laboratory with the standard rearing procedures for light-dark exposure cycle (12 h each) along with consistent availability of food (Boiled Dahlia, i.e., coarsely crushed wheat) and water as per the recommendation of Committee for the Purpose of Control and Supervision on Experimental Animals (CPCSEA) guidelines, Ministry of Forests and Environment, Government of India. Animals were accustomed to new laboratory environment for minimum of 1 week prior to execution of behavioral experiment. All the experiments were conducted between 09:00 and 17:00 h. Protocol for behavioral experiments carried out in this study was approved by the Institutional Animals Ethics Committee (IAEC) with reference number (Reg No. 0436).

\section{Experimental design}

Total of 43 mice groups and 5 rat groups were employed (Table 1) to carry out the experiments. Minimum of six animals were taken in each group $(n=6)$. Positive control 


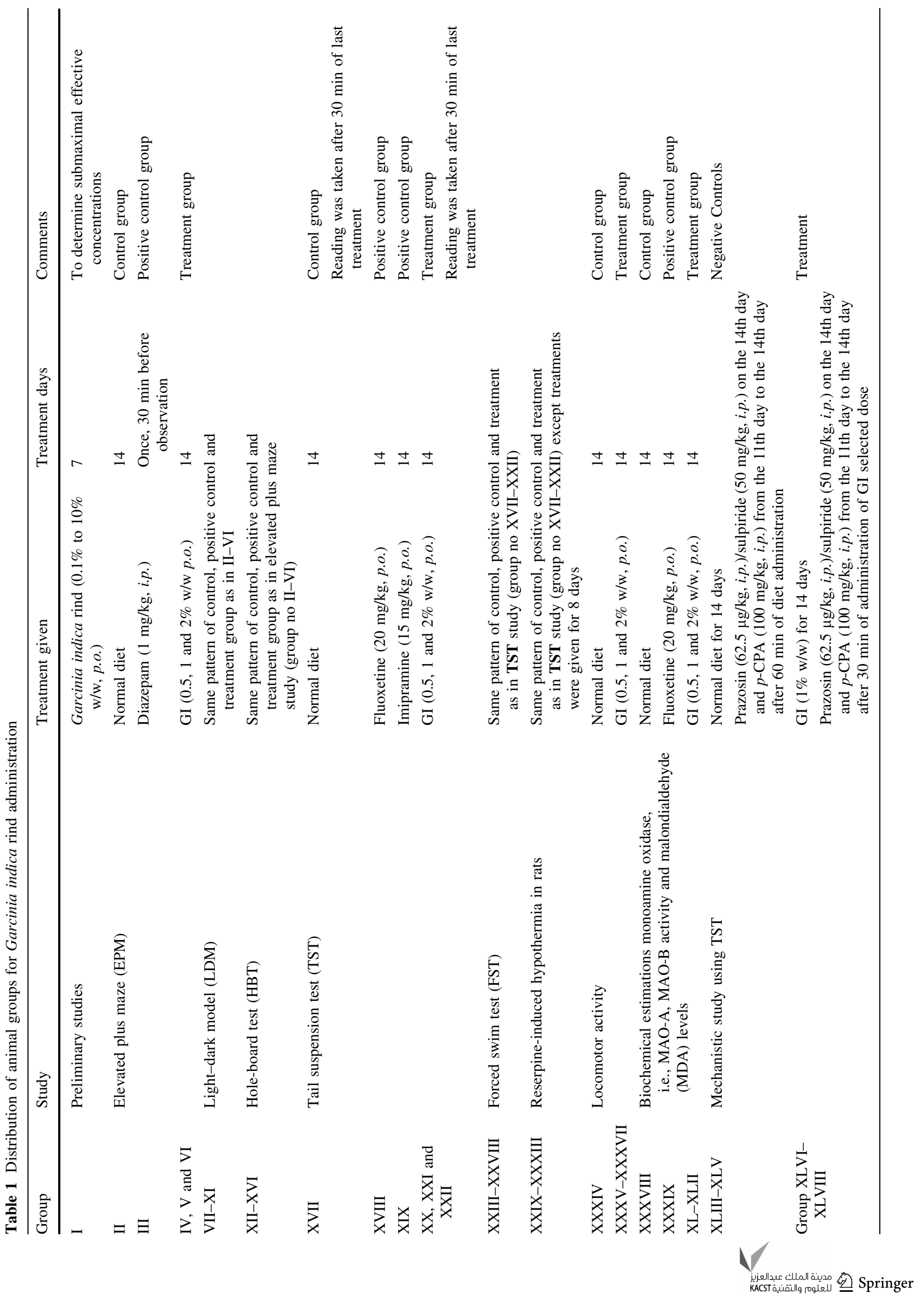


groups were given diazepam (a reference standard anxiolytic) at dose $1 \mathrm{mg} / \mathrm{kg}$; i.p., imipramine and fluoxetine (standard antidepressant agents) at dose 15 and $20 \mathrm{mg} / \mathrm{kg}$, p.o., respectively. The drugs were administered $0.5 \mathrm{~h}$ prior to the conduct of behavioral studies. While $G$. indica rind was administered at the concentrations of $0.5,1$, and $2 \%$ w/w as a mixture with diet; for 14 consecutive days to mice for behavioral experiments and biochemical estimations; and for 8 days to rats for reserpine-induced hypothermia model. $0.5 \mathrm{~h}$ past to the administration of the final dosage (on the 14th day), mice were given exposure to elevated plus maze (EPM) model, light-dark model (LDM), holeboard test (HBT), forced swim test (FST), and tail suspension test (TST), while rats were checked for a change in temperature in reserpine-induced hyperthermia model on the 8th day.

\section{Anxiety models}

\section{Elevated plus maze (EPM)}

EPM comprises of a plus sign maze having (a) central platform with four arms: two of which are (b) open and other two are (c) close with dimensions (a) $5 \times 5 \mathrm{~cm}$, (b) $16 \times 5 \mathrm{~cm}$, and (c) $16 \times 5 \times 15 \mathrm{~cm}$, respectively, while maze height is $25 \mathrm{~cm}$ from ground. EPM uses the fear of open arm and elevation to induce anxiety in animals. $0.5 \mathrm{~h}$ after the last treatment, each animal was individually kept at the central platform of maze and recordings of their behavior were taken for $5 \mathrm{~min}$. The number of times the animal entered into both, open and closed arms and duration(s) of the same were documented. Entry into an arm was taken into account only when all four paws of the animal came inside the particular arm. Tests were performed in an isolated quite room to avoid any type of turbulence in the behavior of animals (Tanyeri et al. 2013).

\section{Light-dark model (LDM)}

LDM comprises of a rectangular box divided by an opaque partition into two chambers, i.e., one dark and one lit chamber. Dimensions of two compartments were $25 \times 25 \times 25 \mathrm{~cm}$ with transit hole of $5 \times 5 \mathrm{~cm}$ in dividing wall. Dark compartment was covered from top and was pasted with black chart from inside, while lit compartment was open, pasted with white chart from inside, and was illuminated with $40 \mathrm{~W}$ light source kept $25 \mathrm{~cm}$ above the open box. A provision of transit hole, which is present in the divider wall of two compartments with base at the floor, was given to animal for the exploration of both the compartments. Rodent was presented to lit box just after $0.5 \mathrm{~h}$ of treatment with test drug or vehicle or standard drug.
Number of times the animal shifted from one box to another and the duration(s) for which animal remained in each compartment were recorded for $10 \mathrm{~min}$. This model utilizes the instinctive repulsion of rodents for intensely illuminated area, causing anxiety-like behavior in animals (Bourin and Hascoet 2003; Dhingra et al. 2012a).

\section{Hole-board test (HBT)}

Method for HBT was adopted from the literature with little modifications. It consists of a wooden board having dimensions of $40 \times 40 \times 25 \mathrm{~cm}^{3}$ along with uniformly dispersed 16 holes each having constant diameter of $3 \mathrm{~cm}$. Animal was placed at the center of hole board after the administration of given treatments and its activity was observed for a duration of $5 \mathrm{~min}$. The number of head dips was taken into account in this behavioral paradigm. Head dips indicate exploratory behavior of mice, which is assumed as anxiolytic behavior of animal (Boissier and Simon 1964; Crawley 1985; Kumar et al. 2012; Yadav et al. 2008).

\section{Depression models}

\section{Forced swim test (FST)}

FST was performed on mice to test antidepressant activity (Porsolt et al. 1977). In this model, mice were enforced to swim in a constrained area. It produces a mental condition of hopelessness (despair behavior) in rodents, which was accounted in the form of immobility period, resembling to human depressed state (Willner 1984). The apparatus used for FST was an open glass chamber having dimensions $25 \times 15 \times 25 \mathrm{~cm}$, occupied with fresh water up to level of $15 \mathrm{~cm}$ with temperature $25 \pm 3{ }^{\circ} \mathrm{C}$. After $0.5 \mathrm{~h}$ of treatment, animal was dropped down in water and its activity was documented for $6 \mathrm{~min}$. The initial vigorous activity for 2 min reflected its escape-oriented behavior. The activity phase was subsided slowly to passive swimming or floating just to keep its head above water, reflected its despair behavior. No reading was taken in the first $2 \mathrm{~min}$, and despair behavior was recorded in the next 4 min. Care was taken that each animal was used once and water should be changed after each animal to avoid any turbulence in readings, due to the odor of the previous animal excreta (Dhingra and Chhillar 2012).

\section{Tail suspension test (TST)}

In this model, immobility is taken as a parameter of helplessness, which is evidenced by zero movement of body of animal or passive hanging. Mice were hung upside down on the side of a table/shelf, using their tail, at $50 \mathrm{~cm}$ 
height from the floor with the aid of adhesive tape for 6 min. The initial dynamic (vigorous) behavior followed by progressive periods of immobility was observed which was aimed at rescuing themselves from the unpleasant situation termed helplessness. The duration of immobility was documented for $6 \mathrm{~min}$, excluding the initial $2 \mathrm{~min}$ of struggling (Dhingra and Chhillar 2012; Rodrigues et al. 2002; Steru et al. 1985).

\section{Reserpine-induced hypothermia model}

Reserpine causes the depletion of biogenic amines in the brain leading to hypothermia in rodents (Sato et al. 2007). The hypothermia is taken as the parameter of depressed behavior, while the rising of body temperature up to normal levels points towards a non-depressed state of mind (Bill et al. 1989). Fruit rind/standard drug was administered for 8 days. The initial rectal temperature was measured before injecting reserpine. Reserpine $(2 \mathrm{mg} / \mathrm{kg}$, s.c.) was injected to animals on the 7th day, $1 \mathrm{~h}$ after administration of fruit rind/standard drug to each group of rats. Rectal temperature was noted again after 18,20, 22, and $24 \mathrm{~h}$ of injecting reserpine, using rectal thermometer. The difference in rectal temperature was observed (Tripathi et al. 2010).

\section{Measurement of locomotor activity}

Actophotometer (Inco, Ambala, India) is used to assess motor coordination. Actophotometer consists of photocells in which continuous light rays falling on photocells display zero reading on digital actophotometer. As the animal moves in actophotometer, disruption of continuous light rays occurs which is recorded and presented as the number of counts. Rearing and ambulation movements were taken as indices of score count. Animal was kept in actophotometer for $5 \mathrm{~min}$. To prevent any turbulence in the reading of an animal, by the odor of the previous animal, ethanol $5 \%$ solution was used to wipe out the surface of activity cage after taking readings from each animal. The locomotor scores were documented before and after the drug treatment as given in the literature (Anderson et al. 1975; Dhingra and Bansal 2014; Gupta et al. 2012).

\section{Biochemical estimations}

Slight anesthesia was given to animals before sacrificing them by cervical decapitation after the administration of the final dose of fruit rind/drug (14th day). Whole brain of animal was vigilantly taken out from the skull just after decapitation and placed on ice. Brain samples were washed with sucrose $(0.25 \mathrm{M})$, tris-EDTA buffer (pH 7.4, $20 \mathrm{mM})$, homogenized, and centrifuged twice at $800 \times g$ for $10 \mathrm{~min}$ at $4{ }^{\circ} \mathrm{C}$. The obtained supernatant was again centrifuged at $12,000 \times g$ for $20 \mathrm{~min}$ at $4{ }^{\circ} \mathrm{C}$ to obtain mitochondrial fraction in the pellet. The pellet was washed with the same buffer using similar centrifugation conditions. Supernatant was used for lipid peroxidation assay or malondialdehyde (MDA)-level estimation, while precipitates were used for MAO estimation (Yoshino et al. 2011). Supernatant as such and precipitates after dissolution were also taken for the estimation of total protein content using Lowry method.

\section{Estimation of MAO-A and MAO-B activities}

Method for MAO activity determination was taken from the literature with little modification (Pan et al. 2005). MAO-A assay mixture, consisting of serotonin (5 hydroxtryptamine, 5-HT, $4 \mathrm{mM}$ ) dissolved in $100 \mathrm{mM}$ sodium phosphate buffer ( $\mathrm{pH}$ 7.4) was mixed with brain mitochondrial fraction $(150 \mu \mathrm{l})$ for carrying out enzymatic reaction. The reaction was allowed to continue for $10 \mathrm{~min}$ and was stopped by the addition of $200 \mu \mathrm{l} 0.5 \mathrm{M} \mathrm{HCl}$. Absorbance was noted down at $280 \mathrm{~nm}$ wavelength using UV-vis spectrophotometer (Varian Cary-5000; Netherland). For estimating MAO-B activity, the same procedure that of MAO-A was followed by replacing the substrate with $100 \mathrm{mM}$ benzylamine and absorbance and was taken at $249 \mathrm{~nm}$ wavelength.

\section{Estimation of malondialdehyde (MDA) levels}

MDA, an index lipid peroxidation and free radical generation (indirectly), was analyzed and represented as equivalents of thiobarbituric acid-reactive substances and was determined by the method as described literature. $4 \mathrm{ml}$ assay mixture was comprised of sodium lauryl sulphate $(0.4 \% \mathrm{w} / \mathrm{v})$, trichloroacetic acid $(7.5 \% \mathrm{w} / \mathrm{v}, \mathrm{pH} 3.5)$, and thiobarbituric acid $(0.3 \% \mathrm{w} / \mathrm{v})$ along with $0.2 \mathrm{ml}$ supernatant of brain homogenate as mentioned earlier. The mixture was heated at $95{ }^{\circ} \mathrm{C}$ for $60 \mathrm{~min}$ and cooled, followed by the addition of $\mathrm{n}$-butanol and pyridine $(15: 1 \mathrm{v} / \mathrm{v})$. The mixture was centrifuged at $3000 \mathrm{rpm}$ for $10 \mathrm{~min}$. Organic layer was segregated and absorbance was taken at $532 \mathrm{~nm}$ in spectrophotometer. The MDA content was represented in $\mathrm{nmol} / \mathrm{mg}$ protein (Okhawa et al. 1979).

\section{Statistical analysis}

Statistical analysis was performed with GraphPad Prism and based on an analysis of variance (ANOVA) followed by Dunnet's test/Tukey's test (mentioned in the caption of resulted graph). A significant difference was established with respect to control group when $p<0.05$. 


\section{Results}

In preliminary studies (to determine the effective range), different concentrations of GI, i.e., 0.5, 2.0, 5.0, and 10.0\% $\mathrm{w} / \mathrm{w}$ in diet, were administered, taking three animals in each group using TST model for depression and EPM model for anxiety. It was found that animal groups treated with $2.0 \% \mathrm{w} / \mathrm{w}$ and above concentrations of GI showed no significant increase in either antidepressant or anti-anxiety activity. Therefore, for further studies, 0.5 to $2 \% \mathrm{w} / \mathrm{w}$ range of concentration was selected.

\section{The effect of Garcinia indica (GI) on laboratory models of anxiety}

In light-dark model, remarkable increase in duration for which animal remained in enlightened compartment (s) exhibited anti-anxiety activity and reverse of the same represented the anxiogenic activity. In HBT model, headdipping behavior reflects the emotional state of animals. GI at concentrations $0.5,1$, and $2 \%, \mathrm{w} / \mathrm{w}$, exhibited a significant increase $(p<0.05)$ in the duration of mice stay in lit box of light-dark model (Fig. 1a). GI at these concentrations showed elevation in head-dip counts in HBT. There was a direct correlation in the dose and head-dip counts in
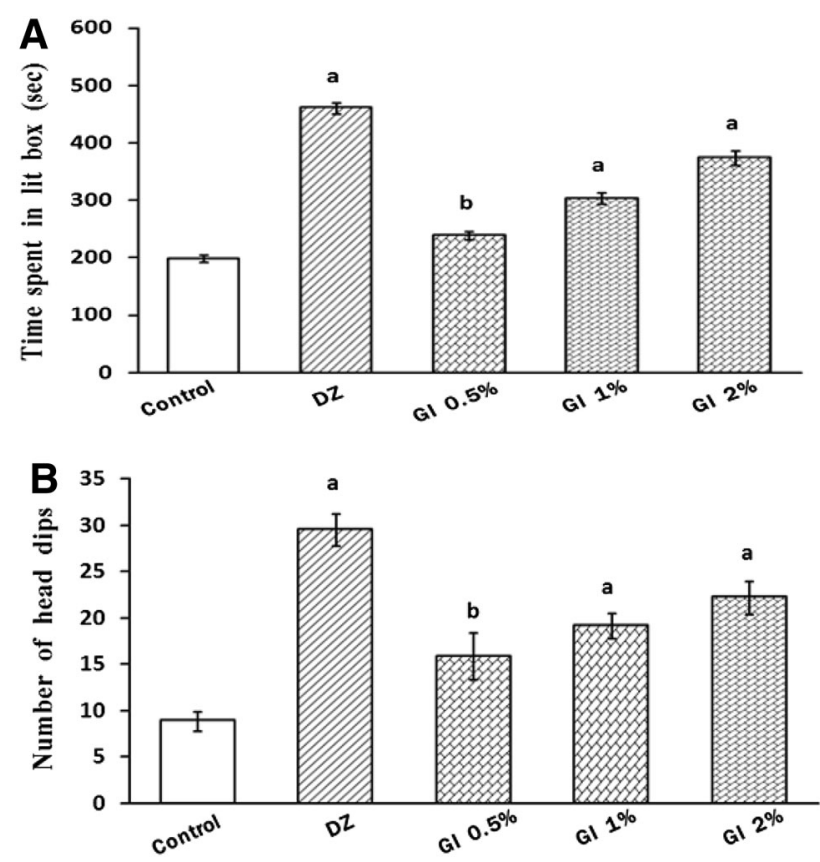

Fig. 1 Effect of Garcinia indica on a time spent in lit box of lightdark model, $\mathbf{b}$ number of head dips in hole-board test. Values are in Mean \pm SEM $(n=6)$, DZ Diazepam $(1 \mathrm{mg} / \mathrm{kg}$, i.p. $)$, GI Garcinia indica $(0.5,1$ and $2 \% \mathrm{w} / \mathrm{w}$, administered along with diet for 14 days), ${ }^{\mathrm{a}} p<0.01$ as compared to control group, ${ }^{\mathrm{b}} p<0.05$ as compared to control group; analyzed by one-way ANOVA followed by Dunnett's $t$ test
HBT (Fig. 1b), although both the outcomes of GI, i.e., time spent and no of head dips, were less than the standard Diazepam (DZ) $1 \mathrm{mg} / \mathrm{kg}$.

In EPM boost in duration of stay and count of entries, in open arms, exhibited anti-anxiety effect. While, lesser entries and less time spent in open arm reflected anxiogenic effect. GI at concentrations $0.5,1$, and $2 \%, \mathrm{w} / \mathrm{w}$, dose dependently $(p<0.05)$ enhanced both the number of entries and time spent in open arms of EPM (Fig. 2).

\section{The effect of Garcinia indica (GI) on laboratory models of depression}

Effect of Garcinia indica (GI) on immobility duration of mice in FST and TST was observed in this study. Immobility depicts a condition in animals known as helplessness, which can be switched by antidepressant agents such as fluoxetine and imipramine. Reduction in immobility exhibits depression-free state. GI at the concentrations $0.5,1$, and $2 \% \mathrm{w} / \mathrm{w}$, when given concomitantly with diet of mice, showed a significant reduction $(p<0.05)$ in the immobility duration of rodent in FST and TST (Fig. 3).

Rectal temperature of rats using reserpine-induced hypothermia model reflects the depletion of noradrenaline and serotonin in brain. GI $(0.5,1$ and $2 \%, w / w)$ was
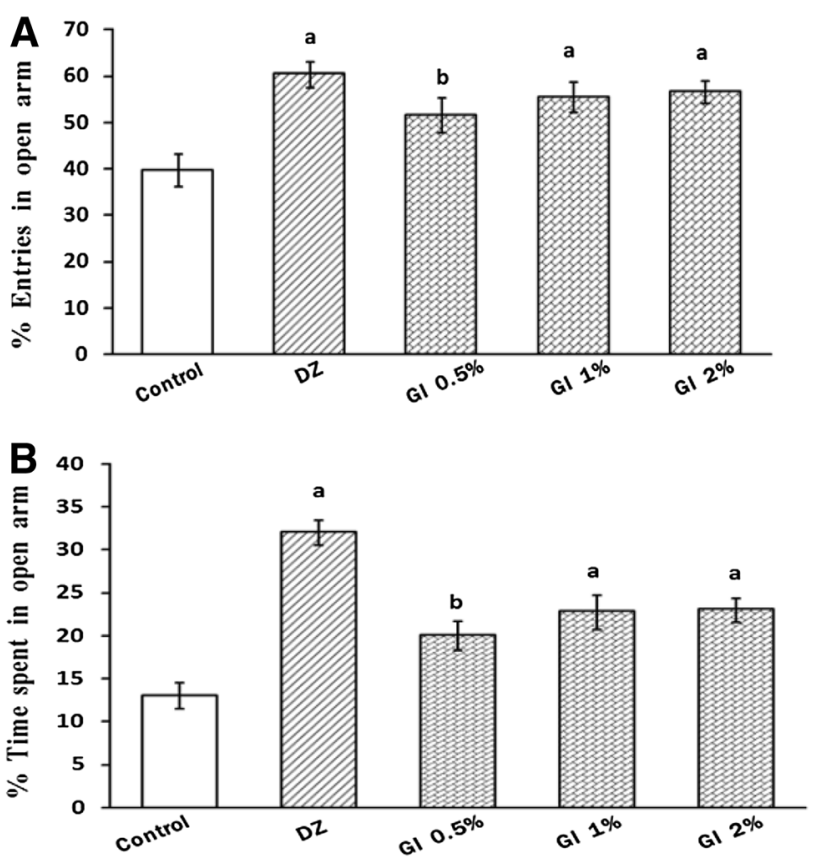

Fig. 2 Effect of Garcinia indica on a open arm entries of Garcinia indica, $\mathbf{b}$ time spent in open arm using elevated plus maze. Values are in Mean \pm SEM $(n=6), D Z$ Diazepam ( $1 \mathrm{mg} / \mathrm{kg}$, i.p. $)$, GI Garcinia indica $(0.5,1$ and $2 \% \mathrm{w} / \mathrm{w}$, administered along with diet for 14 days), ${ }^{\mathrm{a}} p<0.01$ as compared to control group, ${ }^{\mathrm{b}} p<0.05$ as compared to control group; analyzed by one-way ANOVA followed by Dunnett's test 
administered along with diet for 8 days successively to rats. GI at $1 \% \mathrm{w} / \mathrm{w}$ significantly $(p<0.05)$ reversed the hypothermia induced by reserpine (Fig. 4). A significant enhancement in the rectal temperature up to normal levels was observed upon administration of Imipramine (standard
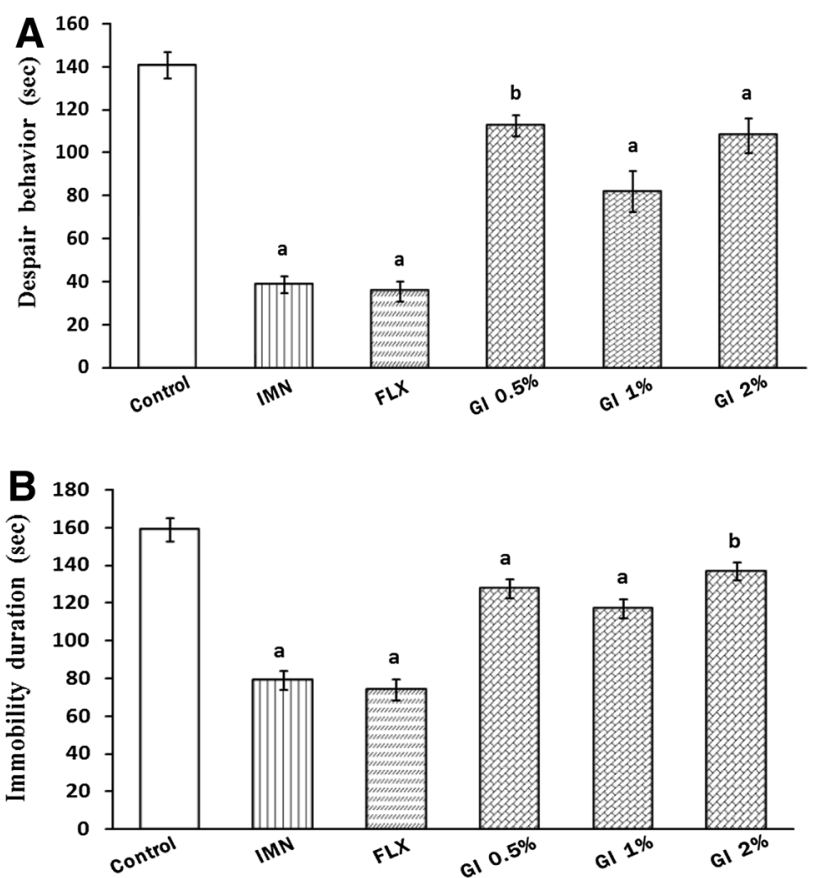

Fig. 3 Effect of Garcinia indica on a despair behavior of mice in forced swim test, $\mathbf{b}$ immobility duration in tail suspension test. Values are in Mean $\pm \operatorname{SEM}(n=6)$, GI Garcinia indica $(0.5,1$, and $2 \%$ $\mathrm{w} / \mathrm{w}$, administered along with diet for 14 days), IMN Imipramine (15 mg/kg, p.o.), FLX Fluoxetine $(20 \mathrm{mg} / \mathrm{kg}$, p.o. $),{ }^{\mathrm{a} p}<0.01$ as compared to control group; ${ }^{\mathrm{b}} p<0.05$ as compared to control group; analyzed by one-way ANOVA followed by Dunnett's test

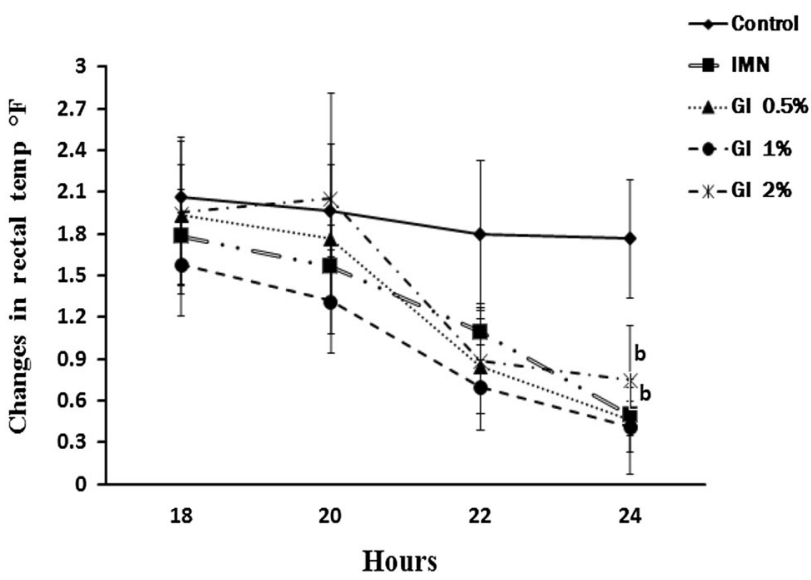

Fig. 4 Effect of Garcinia indica on reserpine-induced hypothermia. Values are in Mean $\pm \operatorname{SEM}(n=6)$; GI Garcinia indica $(0.5,1$, and $2 \% \mathrm{w} / \mathrm{w}$, administered along with diet for 8 days); imipramine (15 mg/kg, p.o.); reserpine: $2 \mathrm{mg} / \mathrm{kg}$, s.c.; ${ }^{\mathrm{a}} p<0.01$ as compared to control group, ${ }^{\mathrm{b}} p<0.05$ as compared to control group; analyzed by one-way ANOVA followed by Dunnett's test drug, positive control group) in comparison with vehicletreated animals (control group).

\section{Effect of Garcinia indica (GI) on brain MAO-A, MAO-B activities, and MDA levels in mice}

GI $8 \% \mathrm{w} / \mathrm{w}$ was co-administered along with food to various animal groups for 14 days and monoamine oxidase enzyme levels (MAO-A and MAO-B) were determined in brain homogenate on the last day of dosage (14th day). It was found that the activity of both the enzymes was significantly $(p<0.05)$ reduced (Fig. 5a, b).

MDA is an indicator of lipid peroxidation. MDA concentrations in samples (brain homogenate) of different animal groups were determined. A direct correlation between dose administered and reduction $(p<0.05)$ in MDA levels was observed with GI treatment, suggesting fall in free radical generation (Fig. 5c).

\section{Effect of Garcinia indica (GI) on locomotor activity of mice}

GI, when admixed with diet of mice at concentration of $0.5,1$, and $2 \% \mathrm{w} / \mathrm{w}$, was not exhibiting difference significantly on locomotor activity in comparison with vehicletreated control group (Fig. 6).

\section{Mechanistic study}

Consequence of combined administration of $G$. indica (GI) with tryptophan hydroxylase inhibitor, i.e., $p$-CPA, $\alpha_{1^{-}}$ adrenoceptor antagonist, i.e., prazosin, and selective $\mathrm{D}_{2^{-}}$ receptor antagonist, i.e., sulpiride on immobility duration in mice subjected to tail suspension test was also checked to confirm the mechanism of action of the functional food in action. Pretreatment of animals with prazosin/sulpiride on the 14th day and $p$-CPA for last 4 days significantly enhanced the passive (immobile) behavior of mice in TST. This increased immobility duration was antagonized by the co-administration of GI $1 \% \mathrm{w} / \mathrm{w}$ in prazosin/sulpiridetreated mice, reflecting the antidepressant effect of GI, while GI did not antagonize the increased immobility duration in $p$-CPA-treated animals (Fig. 7).

\section{Discussion}

Depression and anxiety are dominant form of neuropsychiatric disorders. Depression is a serious but common illness associated with high rates of recurrence and mortality (Kessler et al. 2003). According to WHO, it is predicted that depression is going to be the second most common cause of impairment by 2020 and the first by 2040 
Fig. 5 Effect of Garcinia indica on a brain MAO-A, b MAO-B activity in mice, and c brain MDA levels in mice. Values are in Mean \pm SEM $(n=6), F L X$ Fluoxetine (20 mg/kg, p.o.); GI Garcinia indica $(0.5,1$ and $2 \% \mathrm{w} / \mathrm{w}$, administered along with diet for 14 days); ${ }^{\mathrm{a}} p<0.01$ as compared to control group; ${ }^{\mathrm{b}} p<0.05$ as compared to control group. Analyzed by oneway ANOVA followed by Dunnett's test
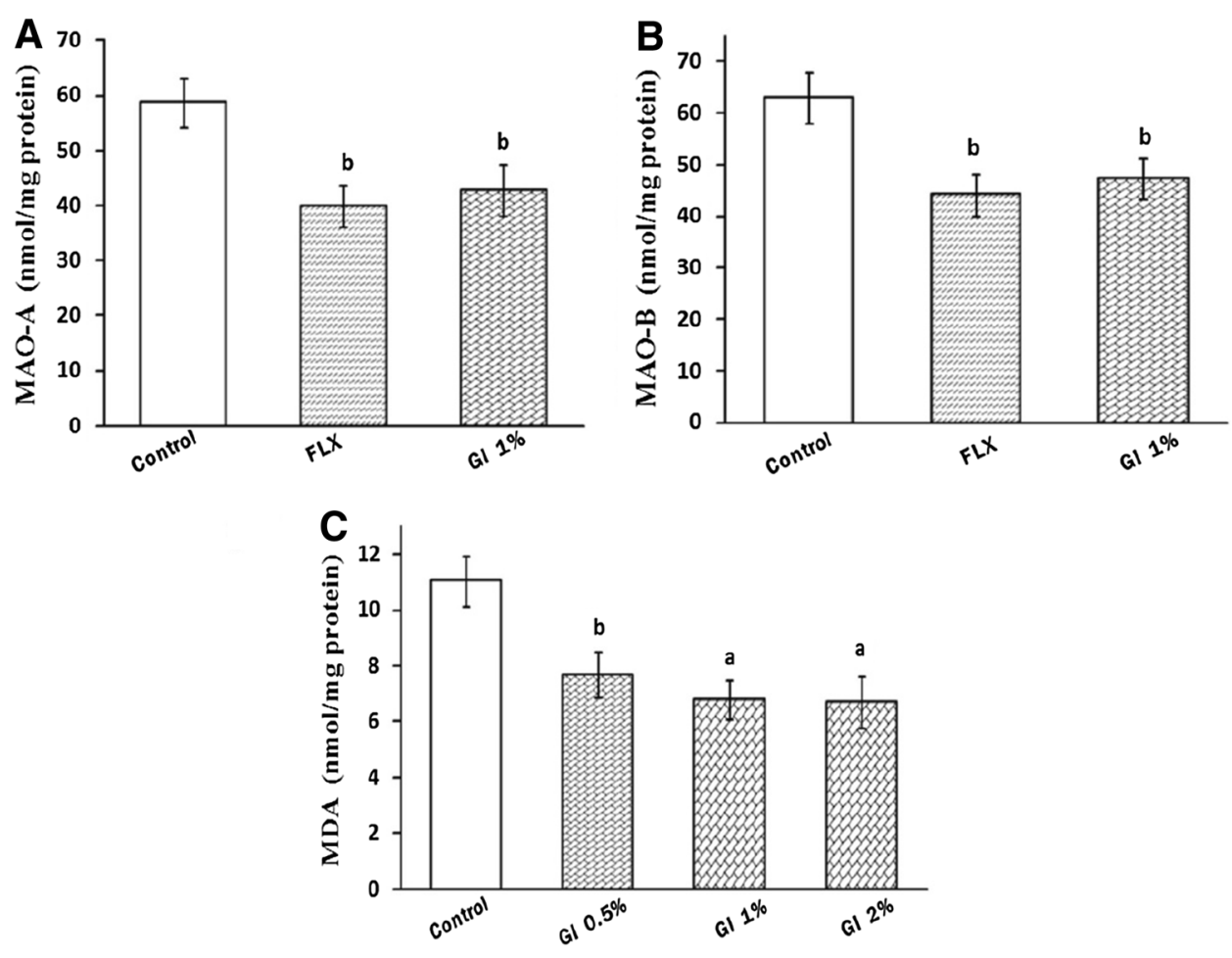

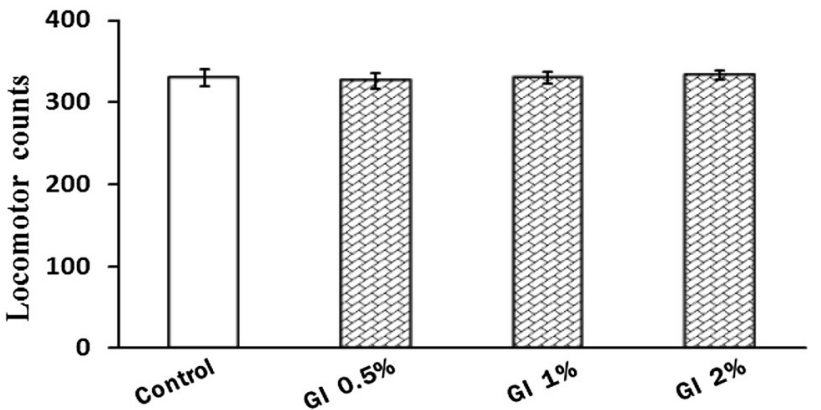

Fig. 6 Effect of Garcinia indica on locomotor activity of mice. Values are in Mean $\pm \operatorname{SEM}(n=6)$; GI Garcinia indica $(0.5,1$, and $2 \% \mathrm{w} / \mathrm{w}$, administered along with diet for 14 days); ${ }^{\mathrm{a}} p<0.01$ as compared to control group; ${ }^{\mathrm{b}} p<0.05$ as compared to control group; analyzed by one-way ANOVA followed by Dunnett's test

(Reddy 2012). The unnecessary fear and worry exorbitant to the nature of threat describes an apathetic emotional state known to be anxiety.

Long-term administration of Kokam fruit rind (GI) for 2 weeks consecutively revealed its anxiolytic efficacy in mice. Kokam fruit rind enhanced the time spent in illuminated section of LDM, raised head-dip counts in the HBT, and enhanced both the count of entries and staying time in open arm of EPM. These findings revealed antianxiety potential of Kokam. The fruit rind of Kokam holds an appreciable quantity of nutrient, hydroxycitric acid (HCA), which has been already established as booster of serotonin liberator from rat brain (Ohia et al. 2000). This

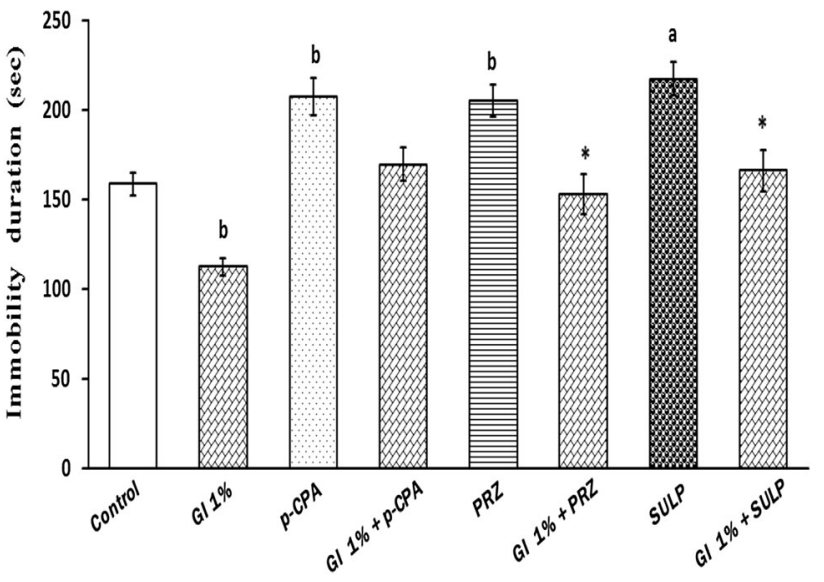

Fig. 7 Effect of combination of Garcinia indica with $p$-CPA/ prazosin/sulpiride. Values are in Mean $\pm \operatorname{SEM}(n=6)$; GI Garcinia indica $(1 \% \mathrm{w} / \mathrm{w}$, administered along with diet for 14 days); $p$-CPA para-chlorophenylalanine $(100 \mathrm{mg} / \mathrm{kg}$, i.p.); $P R Z$ prazosin $(62.5 \mu \mathrm{g} /$ $\mathrm{kg}$, i.p.); SULP sulpiride $(50 \mathrm{mg} / \mathrm{kg}$, i.p. $) ;{ }^{\mathrm{a}} p<0.01$ as compared to control; ${ }^{\mathrm{b}} p<0.05$ as compared to control; $* p<0.05$ as compared to $p$-CPA/prazosin/sulpiride; analyzed by one-way ANOVA followed by Tukey's test

profile of Kokam justifies its use as functional food in depression and anxiety.

In FST, rodent initially displays escape orientation behaviors; however, their behavior changes eventually into the movement that are just sufficient to keep their heads above the water-termed 'despair behavior'. Behavioral despair illustrates that the animal has lost the motivation to 
perform escape-oriented behavior (Porsolt et al. 1977). TST is predicted to give less stress in animals with more pharmacological sensitivity when compared to FST (Thierry et al. 1986; Zeni et al. 2011). In this test, animals show vigorous activity followed by progressive periods of immobility, aimed at rescuing themselves from the unpleasant situation termed helplessness. Diminution of monoamines mainly serotonin and noradrenaline in brain gives an indication of depressive state, which may be due to an increase in monoamine oxidase-MAO activity (Brigitta 2002). Reserpine is reported to lessen down the concentration of noradrenaline (NA), adrenaline, serotonin (5HT), and dopamine (DA). Depletion of these biological amines in the brain causes depression, representing hypothermia in rodents. Whereas, rise in body temperature to normal level gives an indication that mind has been relieved of stress or depression. Reserpine-induced hypothermia model is used to screen potential antidepressant agents (Wang et al. 2016). Kokam reduced the behavior of hopelessness in FST as indicated by decreased immobility period, declined passive behavior in TST, and reversed the hypothermia in reserpine-induced hypothermia model, exhibiting its antidepressant potential. Since Kokam showed no remarkable difference in the movement of mice in actophotometer, there is no probability of psychostimulant effect of this functional food.

Furthermore, the consequence of conjunction of Kokam with various standard inhibitors' monoaminergic system was investigated in rodents. $\alpha_{1}$ adrenoceptor antagonist, i.e., prazosin, 5-HT synthesis inhibitor, i.e., $p$-CPA, and $\mathrm{D}_{2}$ dopamine antagonist, i.e., sulpiride, produced an increase in immobility duration using TST in mice. The effect may be the outcome of declined: noradrenergic activity, serotonin synthesis, and dopamine activity, which are ascribed to $\alpha_{1}$ adrenergic receptors, 5-HT and $\mathrm{D}_{2}$-receptors blockade, respectively (Brod et al. 2016; Dhingra et al. 2012b). Kokam treatment exhibited tremendous results by significantly attenuating the prazosin and sulpiride-induced depressant effect, but was not able to significantly reverse the depressant action of $p$-CPA. Therefore, it can be concluded that the Kokam was involved in adrenergic $\alpha_{1}$ receptor and dopamine $D_{2}$-receptors pathways for the antidepressant effect. The above effect can be attributed to collaborative action of multiple active constituents of Kokam. Inhibition of MAO causes decline in metabolism of biogenic amines consequently leading to their increased levels. In case of depression, 5-HT and NE levels are reduced (Arakawa et al. 2012). Chronic administration of Kokam for 2 weeks displayed a significant inhibition of monoamine oxidase (MAO) activity, thereby elevating the levels of 5-HT and NE. Therefore, it can be interpreted that Kokam action is associated with inhibitory activity of monoamine oxidase (MAO), resulting in the enhancement of the brain concentrations of NE and 5-HT, which in turn induce favourable effects on depression. It was found that Lilium brownii showed an evidence of prevailed and selective MAO-B inhibitory activity, which in response accentuates monoamine levels in the brain. This may be the probable reason of its anxiolytic and antidepressant activity (Doron et al. 2012). Similar results were found in G. indica treated animals.

Free radicals impart remarkable participation in the pathophysiology of anxiety and depression by causing oxidative stress, in addition to GABAergic and serotonergic systems. Reactive oxygen species (ROS) leads to brain damage by disrupting neurons. ROS includes catalase, superoxide anion, peroxide, hydroxyl radicals, singlet oxygen, and nitric oxide (Coyle and Puttfarcken 1993). Excess of ROS disrupts brain defense systems causing the initiation of lipid peroxidation followed by the disorientation of membrane proteins, culminating into cell death. Furthermore, the oxidation of nucleic acids and neurotransmitters affects neuronal function in an unfavorable manner exhibiting detrimental effects on CNS (Bouayed et al. 2009). Literature survey demonstrated that oxidative stress and anxiety/depression are correlated. Patients suffering from these psychological disorders are found to be deficient in antioxidants (Bilici et al. 2001). Thus, a maintained level of antioxidant is required in brain to scavenge excess of ROS and prevent disruption of cell preventing their oxidation (Dhamija et al. 2014). MDA is a marker for lipid peroxidation which is in turn induced by free radicals. Raised levels of MDA depict more free radical generation, indicating disruption to brain cells, while reduced MDA levels correspond to protective effect on brain by decreasing free radicals (Dhamija et al. 2013). Chronic administration of Kokam for 14 days reduced brain MDA levels, indicating diminished free radical generation in mice, thereby protecting the brains of mice from oxidative damage. Furthermore, anti-anxiety and antidepressant activity of this functional food may be accredited the activation of GABAergic receptors by phytoconstituents such as garcinol in Kokam. The antioxidant activity of Kokam is attributed to garcinol and anthocyanins present in it, both of which act as a potential free radical scavenger (Baliga et al. 2011). Garcinol shows strong antioxidant activity due to the presence of phenolic hydroxyl groups and $\beta$-diketone moiety (Padhye et al. 2009). These studies are in line with our previous work, where Tamarindus indica pulp showed potential antioxidant profile due to the presence of flavonoids and polyphenols (Parle and Dhamija 2012). Synergistic effect of exogenous antioxidants (diet) and endogenous antioxidants is well established in quenching free radicals. Dietary foodstuff encompasses flavonoids, vitamins such as $\mathrm{E}$ and $\mathrm{C}$, polyphenols, carotenoids, tannins, etc. as the major 
antioxidants. Therefore, the Kokam fruit rind administered chronically along with diet in this study might have supplemented the effects of endogenous antioxidants, thereby protecting the brain from developing anxiety/depression. Kokam serve as a good source of flavonoids and polyphenols when supplemented with diet. Co-morbidity is a quite common incidence in psychiatric disorders. Previous reports revealed that half of psychologically ill patients suffer from two or more diseased patterns (Kessler et al. 2005). Therefore, it is not surprising that depression and anxiety frequently co-occur, although they represent distinct phenotypes. The co-morbidity between anxiety and depression disorders is as high as 50-60\% (Kaufman and Charney 2000). Furthermore, some symptoms such as isolation from society, sleep impairment, appetite disturbance, fatigue, etc. overlap in both the disorders. Therefore, psychiatrists prescribe anti-anxiety agents such as alprazolam or venlafaxine in depression as well. Therefore, Kokam can be prescribed in mixed cases of anxiety and depression.

\section{Conclusion}

Garcinia indica fruit rind, as a functional food, exhibited prominent antidepressant and anxiolytic effect, without impairing locomotor activity, expressing their non-involvement in CNS stimulation. Kokam showed its effect through its contribution in modulation of $\alpha_{1}$ adrenergic and $\mathrm{D}_{2}$ dopaminergic receptors, as evidenced by its mechanistic study. This effect has been attributed to flavonoids, hydroxycitric acid, garcinol, and anthocayanins present in Kokam. However, detailed studies need to be carried out on large scale at preclinical and/or clinical level to obtain the results with high statistical significance or high level of confidence. The use of Kokam in mixed anxiety and depressive syndrome is always preferred due to its proven anxiolytic and antidepressant potential within equivalent range of dose.

Acknowledgements Ms Isha Dhamija acknowledges University Grant Commission (UGC), Government of India for providing UGCBSR fellowship.

\section{Compliance with ethical standards}

Conflict of interest The authors declare that they do not have any conflict of interest.

\section{References}

Altman RD, Marcussen KC (2001) Effects of a ginger extract on knee pain in patients with osteoarthritis. Arthritis Rheum $44: 2531-2538$
Anderson PF, Jackson DM, Chesher GB, Malor R (1975) Tolerance to the effects of delta 9-tetrahydrocannabinol in mice on intestinal motility, temperature and locomotor activity. Psychopharmacologia 43:31-36

Antala BV, Patel MS, Bhuva SV, Gupta S, Rabadiya S, Lahkar M (2012) Protective effect of methanolic extract of Garcinia indica fruits in 6-OHDA rat model of Parkinson's disease. Indian J. Pharmacol 44:683-687

Arakawa S, Shirayama Y, Fujita Y, Ishima T, Horio M, Muneoka K, Iyo M, Hashimoto K (2012) Minocycline produced antidepressant-like effects on the learned helplessness rats with alterations in levels of monoamine in the amygdala and no changes in BDNF levels in the hippocampus at baseline. Pharmacol Biochem Behav 100:601-606

Baliga MS, Bhat HP, Pai RJ, Boloor R, Palatty PL (2011) The chemistry and medicinal uses of the underutilized Indian fruit tree Garcinia indica Choisy (kokum): a review. Food Res Int 44:1790-1799

Bilici M, Efe H, Koroglu MA, Uydu HA, Bekaroglu M, Deger O (2001) Antioxidative enzyme activities and lipid peroxidation in major depression: alterations by antidepressant treatments. J Affect Disord 64:43-51

Bill DJ, Hughes IE, Stephens RJ (1989) The thermogenic actions of alpha 2-adrenoceptor agonists in reserpinized mice are mediated via a central postsynaptic alpha 2-adrenoceptor mechanism. Br J Pharmacol 96:133-143

Boissier JR, Simon P (1964) Dissociation de deux composantes dans le comportement dinvestigation de la souris. Arch Int Pharmacodyn Ther 147:372

Bouayed J, Rammal H, Soulimani R (2009) Oxidative stress and anxiety: relationship and cellular pathways. Oxid Med Cell Longev 2:63-67

Bourin M, Hascoet M (2003) The mouse light/dark box test. Eur J Pharmacol 463:55-65

Braithwaite MC, Tyagi C, Tomar LK, Kumar P, Choonara YE, Pillay V (2014) Nutraceutical-based therapeutics and formulation strategies augmenting their efficiency to complement modern medicine: an overview. J Funct Foods 6:82-99

Brigitta B (2002) Pathophysiology of depression and mechanisms of treatment. Dialogues Clin Neurosci 4:7-20

Brod LMP, Fronza MG, Vargas JP, Luedtke DS, Luchese C, Wilhelm EA, Savegnago L (2016) Involvement of monoaminergic system in the antidepressant-like effect of (octylseleno)-xylofuranoside in the mouse tail suspension test. Prog Neuropsychopharmacol Biol Psychiatry 65:201-207

Chatterjee A, Bagchi D, Yasmin T, Stohs SJ (2005) Antimicrobial effects of antioxidants with and without clarithromycin on Helicobacter pylori. Mol Cell Biochem 270:125-130

Chen G, Bower KA, Xu M, Ding M, Shi X, Ke Z-J, Luo J (2009) Cyanidin-3-glucoside reverses ethanol-induced inhibition of neurite outgrowth: role of glycogen synthase kinase 3 beta. Neurotox Res 15:321-331

Coyle JT, Puttfarcken P (1993) Oxidative stress, glutamate and neurodegenerative disorders. Science 262:689-695

Crawley JN (1985) Exploratory behavior models of anxiety in mice. Neurosci Biobehav Rev 9:37-44

Darji KK, Shetgiri P, D'mello PM (2010) Evaluation of antioxidant and antihyperlipidemic activity of extract of Garcinia indica. Int J Pharm Sci Res 1:175-181

Deore AB, Sapakal VD, Naikwade NS (2011) Antioxidant and Hepatoprotective activity of Garcinia indica Linn fruit rind. Pharmacie Globale-Int J Comp Pharm 2:1-5

Dhamija I, Parle M (2012) A natural way to keep depression miles away. Int Res J Pharm 3:475-479

Dhamija I, Kumar N, Manjula SN, Parihar V, Setty MM, Pai KSR (2013) Preliminary evaluation of in vitro cytotoxicity and in vivo 
antitumor activity of Premna herbacea Roxb. in Ehrlich ascites carcinoma model and Dalton's lymphoma ascites model. Exp Toxicol Pathol 65:235-242

Dhamija I, Kumar N, Pai KSR, Setty MM, Kumar S, Jana AK (2014) Exploration of antioxidant and antimicrobial potential of methanolic extract of root stock of Premna herbacea Roxb. Bang J Pharmacol 9:663-664

Dhingra D, Bansal Y (2014) Antidepressant-like activity of betacarotene in unstressed and chronic unpredictable mild stressed mice. J Funct Foods 7:425-434

Dhingra D, Chhillar R (2012) Antidepressant-like activity of ellagic acid in unstressed and acute immobilization-induced stressed mice. Pharm Rep 64:796-807

Dhingra D, Chhillar R, Gupta A (2012a) Antianxiety-like activity of gallic acid in unstressed and stressed mice: possible involvement of nitriergic system. Neurochem Res 37:487-494

Dhingra D, Joshi P, Gupta A, Chhillar R (2012b) Possible involvement of monoaminergic neurotransmission in antidepressant-like activity of Emblica officinalis fruits in mice. CNS Neurosci Ther 18:419-425

Ding M, Feng R, Wang SY, Bowman L, Lu Y, Qian Y, Castranova V, Jiang BH, Shi X (2006) Cyanidin-3-glucoside, a natural product derived from blackberry, exhibits chemopreventive and chemotherapeutic activity. J Biol Chem 281:17359-17368

Doron R, Lotan D, Rak-Rabl A, Raskin-Ramot A, Lavi K, Rehavi M (2012) Anxiolytic effects of a novel herbal treatment in mice models of anxiety. Life Sci 90:995-1000

Elisia I, Kitts DD (2008) Anthocyanins inhibit peroxyl radicalinduced apoptosis in Caco-2 cells. Mol Cell Biochem 312:139-145

Gupta G, Kazmi I, Afzal M, Rahman M, Saleem S, Ashraf MS, Khusroo MJ, Nazeer K, Ahmed S, Mujeeb M (2012) Sedative, antiepileptic and antipsychotic effects of Viscum album L. (Loranthaceae) in mice and rats. J Ethnopharmacol 141:810-816

Hadipour-Jahromy M, Mozaffari-Kermani R (2010) Chondroprotective effects of pomegranate juice on monoiodoacetate induced osteoarthritis of the knee joint of mice. Phytother Res 24:182-185

Hemshekhar M, Sunitha K, Santhosh MS, Devaraja S, Kemparaju K, Vishwanath BS, Niranjana SR, Girish KS (2011) An overview on genus garcinia: phytochemical and therapeutical aspects. Phytochem Rev 10:325-351

Jagtap P, Bhise K, Prakya V (2015) A phytopharmacological review on Garcinia indica. Int J Herb Med 3:2-7

Jayaprakasha GK, Sakariah KK (2002) Determination of organic acids in leaves and rinds of Garcinia indica (Desr.) by LC. J Pharm Biomed Anal 28:379-384

Kaufman J, Charney D (2000) Comorbidity of mood and anxiety disorders. Depress Anxiety 12:69-76

Kessler RC, Berglund P, Demler O, Jin R, Koretz D, Merikangas KR, Rush AJ, Walters EE, Wang PS (2003) The epidemiology of major depressive disorder: results from the National Comorbidity Survey Replication (NCS-R). JAMA 289:3095-3105

Kessler RC, Chiu WT, Demler O, Merikangas KR, Walters EE (2005) Prevalence, severity, and comorbidity of 12-month DSM-IV disorders in the National Comorbidity Survey Replication. Arch Gen Psychiatry 62:617-627

Khatib NA, Pawase K, Patil PA (2010) Evaluation of antiinflammatory activity of Garcinia indica fruit rind extracts in wistar rats. Int J Res Ayur Pharm 1:449-454

Krishnamurthy N, Lewis YS, Ravindranath B (1982) Chemical constituents of Kokum fruit rind. J Food Sci Technol 19:97-100

Kumar B, Kuhad A, Chopra K (2011) Neuropsychopharmacological effect of sesamol in unpredictable chronic mild stress model of depression: behavioral and biochemical evidences. Psychopharmacology 214:819-828
Kumar D, Bhat ZA, Kumar V, Khan NA, Chashoo IA, Zargar MI, Shah MY (2012) Effects of Stachys tibetica essential oil in anxiety. Eur J Integ Med 4:e169-e176

Kunnumakkara AB, Koca C, Dey S, Gehlot P, Yodkeeree S, Danda D, Sung B, Aggarwal BB (2009) Traditional uses of spices: an overview Molecular targets and therapeutic uses of spices. World Scientific, New Jersey. http://www.worldscientific.com/ doi/suppl/10.1142/7150/suppl_file/7150_chap01.pdf. Accessed 22 Jan 2016

Kuptniratsaikul V, Thanakhumtorn S, Chinswangwatanakul P, Wattanamongkonsil L, Thamlikitkul V (2009) Efficacy and safety of Curcuma domestica extracts in patients with knee osteoarthritis. J Altern Complement Med 15:891-897

Liao CH, Ho CT, Lin JK (2005) Effects of garcinol on free radical generation and $\mathrm{NO}$ production in embryonic rat cortical neurons and astrocytes. Biochem Biophys Res Commun 329:1306-1314

Malik SK, Chaudhury R, Kalia RK (2005) Rapid in vitro multiplication and conservation of Garcinia indica: a tropical medicinal tree species. Sci Hortic (Amst) 106:539-553

Martin DS, Breitkopf NP, Eyster KM, Williams JL (2001) Dietary soy exerts an antihypertensive effect in spontaneously hypertensive female rats. Am J Physiol Regul Integr Comp Physiol 281:R553-R560

Mayura DN, Kuppast IJ, Virupaksha JH, Ravi MC (2014) A review on Garcinia indica. Int J Uni Pharm Bio Sci 3:309-321

Molina F, López-Acedo E, Tabla R, Roa I, Gómez A, Rebollo JE (2015) Improved detection of Escherichia coli and coliform bacteria by multiplex PCR. BMC Biotechnol 4:15-48

Nayak CA, Rastogi NK (2010) Forward osmosis for the concentration of anthocyanin from Garcinia indica Choisy. Sep Puri Tech $71: 144-151$

Ohia SE, Awe SO, LeDay AM, Opere CA, Bagchi D (2000) Effect of hydroxycitric acid on serotonin release from isolated rat brain cortex. Res Commun Mol Pathol Pharmacol 109:210-216

Okhawa H, Ohishi T, Yagi K (1979) Assay of lipid peroxides in animals tissue by thiobarbituraic acid reaction. Anal Biochem 95:351-358

Padhye S, Ahmad A, Oswal N, Sarkar FH (2009) Emerging role of Garcinol, the antioxidant chalcone from Garcinia indica Choisy and its synthetic analogs. J Hematol Oncol 2:1-13

Pan Y, Kong L, Xia X, Zhang W, Xia Z, Jiang F (2005) Antidepressant-like effect of icariin and its possible mechanism in mice. Pharmacol Biochem Behav 82:686-694

Parle M, Dhamija I (2012) Anxiolytic potential of Tamarindus indica. Ann Pharm Pharm Sci 3:67-71

Parle M, Dhamija I (2013a) Golden benefits of drinking kokam-cola. Int Res J Pharm 4:5-9

Parle M, Dhamija I (2013b) Where there is a Til, there is a will. J Pharm Sci Inno 2:37-40

Porsolt RD, Le Pichon M, Jalfre ML (1977) Depression: a new animal model sensitive to antidepressant treatments. Nature 266:730-732

Preuss HG, Bagchi D, Bagchi M, Rao CVS, Satyanarayana S, Dey DK (2004) Efficacy of a novel, natural extract of (-)-hydroxycitric acid (HCA-SX) and a combination of HCA-SX, niacinbound chromium and Gymnema sylvestre extract in weight management in human volunteers: a pilot study. Nutr Res 24:45-58

Reddy MS (2012) Depression-the global crisis. Indian J Psychol Med 34:201-203

Rodrigues AS, da Silva GL, Mateussi AS (2002) Involvement of monoaminergic system in the antidepressant-like effect of the hydroalcoholic extract of Siphocampylus verticillatus. Life Sci 70:1347-1358

Sato M, Kitaura K, Minami T, Matsumoto S, Fukuda M (2007) Hypothermia-related testicular toxicity of reserpine in mice. Exp Toxicol Pathol 59:187-195 
Selvi AT, Joseph GS, Jayaprakasha GK (2003) Inhibition of growth and aflatoxin production in Aspergillus flavus by Garcinia indica extract and its antioxidant activity. Food Microbiol 20:455-460

Shui G, Leong LP (2006) Residue from star fruit as valuable source for functional food ingredients and antioxidant nutraceuticals. Food Chem 97:277-284

Steru L, Chermat R, Thierry B, Simon P (1985) The tail suspension test: a new method for screening antidepressants in mice. Psychopharmacology 85:367-370

Swami SB, Thakor NJ, Patil SC (2014) Kokum (Garcinia indica) and its many functional components as related to the human health: a review. J Food Res Tech 2:130-142

Tanyeri P, Buyukokuroglu ME, Mutlu O, Ulak G, Akar FY, Celikyurt IK, Erden BF (2013) Evidence that the anxiolytic-like effects of the beta3 receptor agonist Amibegron involve serotoninergic receptor activity. Pharmacol Biochem Behav 110:27-32

Thierry B, Steru L, Simon P, Porsolt RD (1986) The tail suspension test: ethical consideration. Psychopharmacology 90:284-285

Tripathi S, Tripathi PK, Singh PN (2010) Antidepressant activity of Nyctanthes arbor-tristis leaf extract. Pharmacologyonline 3:415-422

Varalakshmi KN, Sangeetha CG, Shabeena AN, Sunitha SR, Vapika J (2010) Antimicrobial and cytotoxic effects of Garcinia indica fruit rind extract. Am-Eur J Agric Environ Sci 7:652-656
Wang Y, Gao S-M, Li R, Zhang M, Gao S, Yu C-Q (2016) Antidepressant-like effects of the Radix Bupleuri and Radix Paeoniae Alba drug pair. Neurosci Lett 633:14-20

Willner P (1984) The validity of animal models of depression. Psychopharmacology 83:1-16

Yadav AV, Kawale LA, Nade VS (2008) Effect of Morus alba L. (mulberry) leaves on anxiety in mice. Indian $\mathrm{J}$ Pharmacol 40:32-36

Yamaguchi F, Ariga T, Yoshimura Y, Nakazawa H (2000) Antioxidative and anti-glycation activity of garcinol from Garcinia indica fruit rind. J Agric Food Chem 48:180-185

Yoshino S, Hara A, Sakakibara H, Kawabata K, Tokumura A, Ishisaka A, Kawai Y, Terao J (2011) Effect of quercetin and glucuronide metabolites on the monoamine oxidase-A reaction in mouse brain mitochondria. Nutrition 27:847-852

Zeni ALB, Zomkowski ADE, Dal-Cim T, Maraschin M, Rodrigues ALS, Tasca CI (2011) Antidepressant-like and neuroprotective effects of Aloysia gratissima: investigation of involvement of Larginine-nitric oxide-cyclic guanosine monophosphate pathway. J Ethnopharmacol 137:864-874 